\title{
Relative Increase in IgG Antibodies to Pseudomonas aeruginosa 60-kDa GroEL in Prediabetic Patients with Cystic Fibrosis
}

\author{
PER JENSEN, HELLE K. JOHANSEN, SUSANNE LANNG, AND NIELS HØIBY
}

Department of Clinical Microbiology [P.J., H.K.J., N.H.] and The Danish Cystic Fibrosis Centre, Department of Paediatrics, The National University Hospital, Copenhagen, Denmark [S.L., N.H.]

\begin{abstract}
In recent years research has focused on a possible connection between bacterial infection and development of diabetes mellitus. In this study, serum antibody responses against bacterial antigens in diabetic and nondiabetic patients with cystic fibrosis (CF) were evaluated. The first part of the study included $252 \mathrm{CF}$ patients of whom $46(18 \%)$ had diabetes. This study showed that precipitating antibodies (precipitins) against Pseudomonas aeruginosa and other bacteria in crossed immunoelectrophoresis, and $\mathrm{IgG}$ antibodies against a $60-\mathrm{kD}$ GroEL of $P$. aeruginosa, were highly variable and positively correlated with age. Patient material matched for age and sex showed no significant difference between diabetic and nondiabetic CF patients in precipitins or IgG antibodies to $P$. aeruginosa GroEL. Two longitudinal studies of 9 and 5 y using retrospectively selected sera from 29 prediabetic and 29 cross-matched nondiabetic CF patients were performed. As to precipitins against $P$. aeruginosa, we found no difference between the prediabetic and the nondiabetic group of patients during the study period. The study revealed, however, a significant increase of $24.6 \%(p=0.008)$ of $\mathrm{IgG}$ antibodies against $P$. aeruginosa $60-\mathrm{kD}$ GroEL, 3-12 mo before the onset of
\end{abstract}

\section{ABSTRACT}

diabetes in patients with $\mathrm{CF}$, compared with an overall increase of $5 \%$ to $6 \%$ per year in both groups during the observation period. This study shows that diabetes in CF appears after a peak of serum IgG antibodies against GroEL and indicates that development of diabetes in CF patients may not only be caused by a progressive fibrosis of the pancreatic tissue, but may be augmented by a short-term specific immunologic reaction, initially triggered by an ongoing and progressive pulmonary infection. (Pediatr Res 49: 423-428, 2001)

CF, cystic fibrosis
CFDM, diabetes in CF
CIE, crossed immunoelectrophoresis
Hsp, heat shock protein
IGT, impaired glucose tolerance
OGTT, oral glucose tolerance test
NGT, normal glucose tolerance
Precipitins, precipitating antibodies in CIE
IDDM, insulin-dependent type-1 diabetes mellitus

$\mathrm{CF}$ is the most common fatal autosomal recessive inherited disorder in the white population. The most important clinical feature is recurrent and chronic pulmonary infection, of which chronic infection with Pseudomonas aeruginosa is the most serious. In addition, insufficient pancreatic exocrine function and endocrine dysfunction are commonly associated with CF. Recent studies have described a high prevalence of impaired glucose tolerance (18\%) and diabetes mellitus (24\%) in CF patients (1). A variety of experimental data provides compelling evidence that bacterial $60-65 \mathrm{kD}$ hsps may constitute a link between various infectious diseases and autoimmunity

Received March 21, 2000; accepted October 18, 2000.

Correspondence and reprint requests: P. Jensen, Ph.D., Department of Clinical Microbiology, Panum Institute 24.1, Blegdamsvej 3C, DK-2200 Copenhagen N, Denmark.

Supported by The Danish Medical Research Council; grant no. 28809, the Danish Pasteur Society, and the Kong Christian den Tiendes Fond. The European Association for the Study of diabetes (EASD) provided an EASD-Bayer Travel Fellowship for Young Scientists.
(2-7). Hsps of infecting microorganisms are known to constitute a major target of the innate and adaptive immune system. The bacterial $60-65 \mathrm{kD}$ hsps are ubiquitous and have a very high interspecies sequence homology (8). The $60-\mathrm{kD}$ GroEL of $P$. aeruginosa, previously designated common antigen (9), has a sequence homology of $52 \%$ with its human counterpart, hsp60 (8), originally designated P1 (10). Interestingly, various immunizations with peptides of the human hsp60 (p277) have been shown to induce diabetes or transient diabetes in various animal models and are linked to the appearance of hsp60specific T cells (3-5).

The purpose of this study was to investigate in CF patients the possible association between bacterial infection and diabetes. This was accomplished by measuring the number of precipitins in CIE and the level of IgG antibodies specific for the $60-\mathrm{kD}$ GroEL of $P$. aeruginosa in serum of prediabetic and nondiabetic patients with $\mathrm{CF}$. 
Table 1. Cross-sectional analysis of 252 CF patients analyzed for number of bacterial precipitins

\begin{tabular}{lllc}
\hline \multicolumn{1}{c}{ Variable } & \multicolumn{1}{c}{ CFDM $\dagger$} & \multicolumn{1}{c}{ CF alone } & \multicolumn{1}{c}{ All } \\
\hline No. of patients (\%) & $46(18)$ & $206(82)$ & $252(100)$ \\
Age in years (mean, range) & $26(13-45)$ & $15(2-43)$ & $17(2-45)$ \\
Patient with chronic $P$. & $38(83)$ & $108(52)$ & $146(58)$ \\
$\quad$ aeruginosa $(\%)$ & & & \\
Precipitins + (range) & & & \\
P. aeruginosa & $21.4(0-46)^{*}$ & $10.8(0-45)$ & $12.7(0-46)$ \\
S. aureus & $1.3(0-8)$ & $1.5(0-10)$ & $1.4(0-10)$ \\
H. influenzae & $1.5(0-9)$ & $1.5(0-15)$ & $1.4(0-15)$ \\
Others§ & $3.0(0-46)^{*}$ & $1.0(0-34)$ & $1.4(0-46)$ \\
$\quad$ Total precipitins & $28.2(0-96)^{*}$ & $15.5(0-50)$ & $17.8(0-96)$ \\
\hline
\end{tabular}

$* p<0.001$ compared with $\mathrm{CF}$ alone and all.

$\dagger$ Includes CF patients with diagnosed DM (capillary plasma glucose conc. $\geq 12.2 \mathrm{mM}$, determined by 2 -h OGTT.

$\ddagger$ Measured by CIE.

$\S$ Includes Burkholderia cepacia, Pseudomonas maltophilia, Pseudomonas stuzeri, Klebsiella pneumoniae, Enterobacter cloacae, Staphylococcus epidermidis, Serratia marcescens, Nocardia spp., Acinetobacter spp., Agrobacterium spp., and Alcalignes spp.

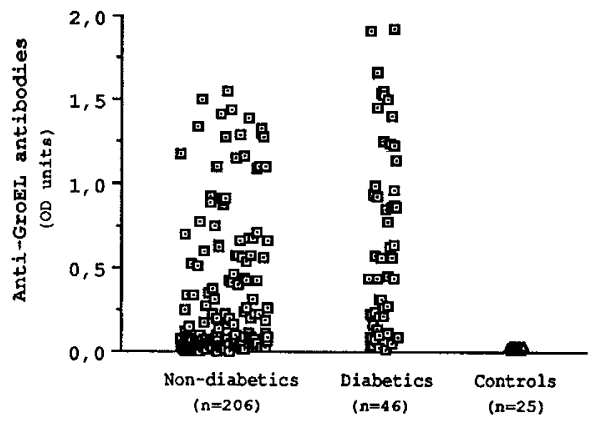

Fig. 1. Cross-sectional study of 252 patients with $\mathrm{CF}$ evaluated for $\mathrm{IgG}$ antibodies against $60-\mathrm{kD}$ GroEL of $P$. aeruginosa. The ordinate indicates the level of GroEL-specific IgG antibodies in OD units determined by immunoblot scanning densitometry. The categories are nondiabetics (mean, $0.28 \mathrm{U}$; range, 0.002-1.928 U), diabetics (mean, $0.69 \mathrm{U}$; range, 0.013-1.912 $\mathrm{U}$ ) and controls (healthy persons; mean, $0.02 \mathrm{U}$; range, $0.012-0.038 \mathrm{U}$ ).

\section{METHODS}

Patients. Danish CF patients attending the Cystic Fibrosis Center in Copenhagen were tested for number of precipitins against $P$. aeruginosa (normal range, $0-1$ ), Staphylococcus aureus (normal range, $0-2$ ), and Haemophilus influenzae (normal range, $0-1$ ) using CIE, and if found by sputum culture also for precipitins against several other microorganisms as previously described $(11,12)$. Glucose tolerance was classified as normal (NGT) if the 2-h postload capillary plasma glucose concentration was $\leq 8.8 \mathrm{mM}$, impaired (IGT) if value was 8.9-12.1 mM, or diabetic (CFDM) if value was $\geq 12.2 \mathrm{mM}$ using a 2-h OGTT according to the 1985 WHO recommendation (13). Serum samples were collected at weekly to 6-mo intervals depending on the patient's clinical condition. All patient sera collected were stored at $-80^{\circ} \mathrm{C}$ until used. Collection of patient serum samples was approved by the patient or parent(s) with informed consent, and by the Ethical Committee of Copenhagen and Frederiksberg, Denmark. Chronic $P$. aeruginosa lung infection was defined as the presence of bacteria in sputum for 6 mo or an antibody response of $\geq 2$ precipitins against $P$. aeruginosa.
Purification of P. aeruginosa 60-kD GroEL. Recombinant GroEL of $P$. aeruginosa was purified as described elsewhere (8). Briefly, primers covering the coding sequence of the $P$. aeruginosa P1118 groEL gene were used in PCR, generating a product of approximately $1.7 \mathrm{kbp}$, which was ligated onto a $p E T 16 b$ expression vector. The ligated material was transformed into competent Escherichia coli, whereafter recombinant material was expressed and purified using a $\mathrm{Ni}^{2+}$ charged His-Bind resin column. The $60-\mathrm{kD}$ GroEL protein was identified using a specific MAb to $P$. aeruginosa $60-\mathrm{kD}$ GroEL, and stored at $-20^{\circ} \mathrm{C}$ until used.

ELISA. Specific IgG antibodies to P. aeruginosa $60-\mathrm{kD}$ GroEL were measured by ELISA. Flat-bottom microdilution plates (96-well, Maxisorb, NUNC, Roskilde, Denmark) were coated with recombinant $P$. aeruginosa GroEL $(2.0 \mu \mathrm{g}$ protein/ well) in PBS, pH 7.2, and incubated overnight. Nonspecific binding was blocked with diluting buffer [PBS, $0.1 \%$ (vol/vol) Tween-20, and $1.5 \%$ (wt/vol) $\mathrm{NaCl}, \mathrm{pH} 7.2]$ for $1 \mathrm{~h}$. Sera in dilutions of 1:1,000 to $1: 100,000$ were applied and incubated for $2 \mathrm{~h}$. The plates were washed three times in PBS-Tween buffer (PBS, 0.1\% Tween-20) and further incubated for $1 \mathrm{~h}$ with a 1:2000 dilution of peroxidase-conjugated rabbit antihuman IgG (P214, Dako A/S, Glostrup, Denmark) in diluting buffer. The plates were washed six times in PBS-Tween buffer and finally developed with $5 \mathrm{mM} o$-phenylenediamide (S2000, Dako A/S, Denmark) in phosphate-citrate buffer ( $35 \mathrm{mM}$ citric acid, $67 \mathrm{mM} \mathrm{Na} \mathrm{HPO}_{4}, \mathrm{pH} 5.0$ ) with $0.0125 \%$ (vol/vol) hydrogen peroxide (Merck, Darmstadt, Germany). The reaction was developed in the dark for $20 \mathrm{~min}$, terminated by the addition of $1 \mathrm{M} \mathrm{H}_{2} \mathrm{SO}_{4}$, and measured at $\mathrm{OD}_{492 \mathrm{~nm}}$ using an automatic plate reader (EIA Reader 2550, Bio-Rad Laboratories, Hercules, CA, U.S.A.). All reactions were performed in $100-\mu \mathrm{L}$ volumes and at room temperature. Antibody levels expressed in units were calculated as the mean of OD values in triplicate assays given as ratio between sample and standard sera. The ratio was converted to units using a high titered anti- $P$. aeruginosa GroEL CF serum as standard assigned 10 $\mathrm{U} / \mathrm{mL}$. The day to day and the interplate variation were determined by testing $10 \mathrm{CF}$ sera in triplicate in ELISA. The day to day variation for the $P$. aeruginosa $\operatorname{IgG}$ GroEL assay was $14 \%$ ( $95 \% \mathrm{CI}, \pm 18 \%)$, and $4 \%(95 \% \mathrm{CI}, \pm 6 \%)$ for the interplate variation. The results for each patient were normalized by calculating the mean of all antibody results obtained during the observation period $($ mean $=100 \%)$. Each observation was expressed as a percentage of the mean value for each patient.

SDS-PAGE, Western blotting, and immunostaining. The SDS-PAGE, Western blotting, and immunostaining were performed essentially as previously described (8).

Laser scanning densitometry. The precipitating bands in immunostaining assays were measured by laser scanning densitometry (diapositive slide, Fuji Velvia, Fujifilm, Copenhagen, Denmark). Photographic dias of immunoblots were scanned with a helium-neon laser scanner (UltroScanXL, LKB 2222, Bromma, Sweden), and the geometric peak area of intensity $\left(\mathrm{OD}_{633 \mathrm{~nm}}\right)$ was integrated automatically. The calculation was $\int \mathrm{AU} \times \mathrm{mm}$, where $\mathrm{AU}$ is absorption (abs) $\mathrm{abs}_{\text {baseline }}$ in units, baseline determined by the 16 lowest points 

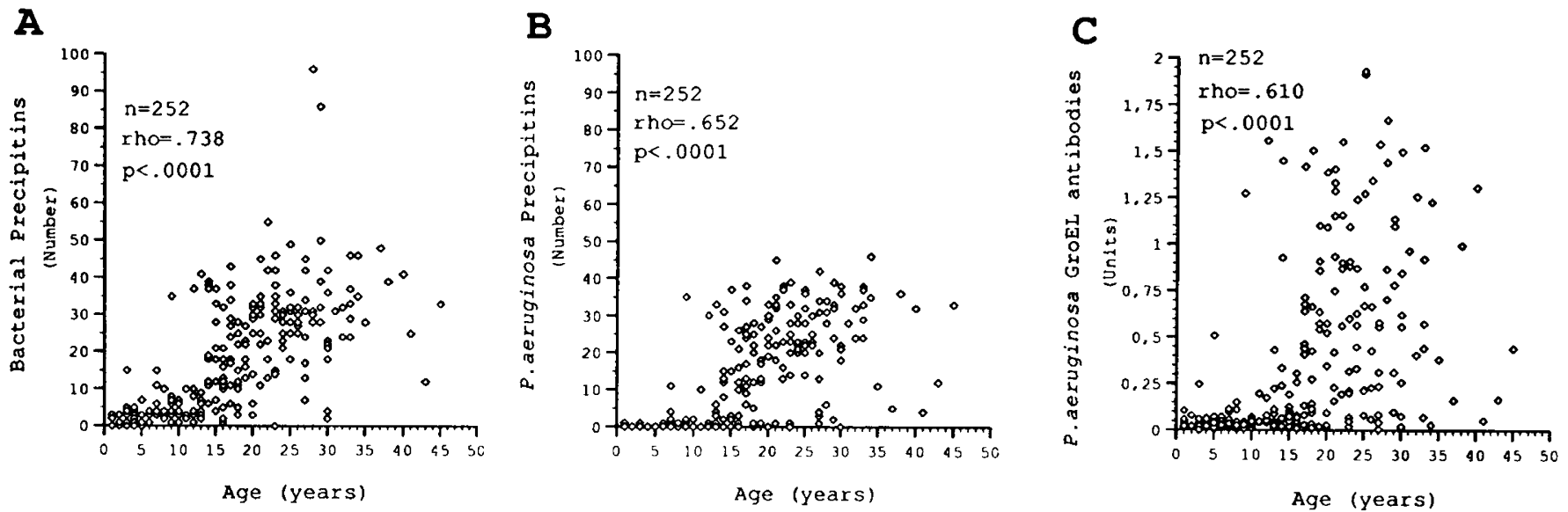

Fig. 2. Cross-sectional analysis showing correlation of total number of bacterial precipitins by CIE $(A)$, $P$. aeruginosa precipitins by CIE $(B)$, and number of IgG antibodies against the $60-\mathrm{kD}$ GroEL of $P$. aeruginosa by immunostaining $(C)$ with age of patients with $\mathrm{CF}$.
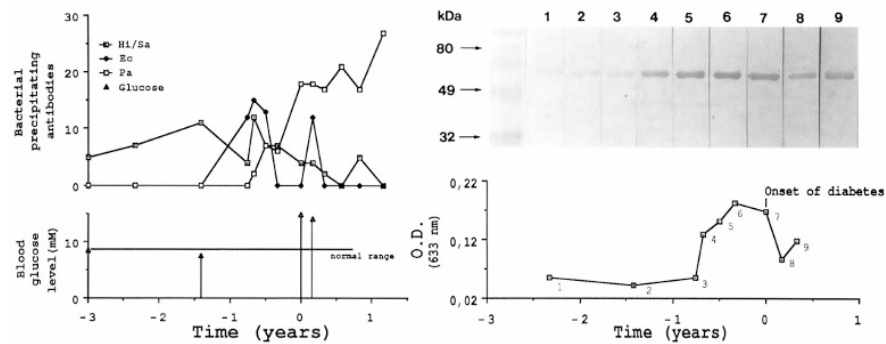

Fig. 3. An 18-year-old girl with $\mathrm{CF}$ who developed CFDM at an age of $15 \mathrm{y}$ was evaluated for number of bacterial precipitins by CIE (Top left), glucose tolerance by OGTT (Bottom left), and IgG antibodies to $P$. aeruginosa $60-\mathrm{kD}$ GroEL by immunostaining (Top right) for a 31-mo period during development of CFDM. Lane 1, sample drawn May 17, 1989; lane 2, sample drawn April 4, 1990; lane 3, sample drawn November 28, 1990; lane 4, sample drawn January 9, 1991; lane 5, sample drawn March 6, 1991; lane 6, sample drawn April 22, 1991; lane 7, sample drawn August 21, 1991; lane 8, sample drawn November 1, 1991; and lane 9, sample drawn January 3, 1992. The patient developed CFDM diagnosed on August 25, 1991, with a 2-h blood glucose level of $14.7 \mathrm{mM}$. An immunoblot scanning assay (Bottom right) revealed an increase of $69.4 \%$ of GroEL-specific IgG antibodies in a 5-mo period (from November 28, 1990, to April 22, 1991), 9 mo before the onset of CFDM. Legends indicate precipitins against $H$. influenzae and $S$. aureus $(\mathrm{Hi} / \mathrm{Sa}), E$. coli $(\mathrm{Ec})$, and $P$. aeruginosa $(\mathrm{Pa})$.

in the scan, and $\mathrm{mm}$ is the peak width at baseline. The peak area was presented in OD units.

Statistics. The following statistical methods were used: Mann-Whitney $U$ test, Spearman rank correlation, Page test, Wilcoxon signed rank test, and linear regression analysis, with a $5 \%$ level of significance. The programs StatView (StatView ver 4.51, Abacus Concepts, Berkeley, CA, U.S.A.), for statistics and CricketGraph (CricketGraph III ver 1.5.3, Computer Associates International, Islandia, NY, U.S.A.), for graphic presentation were used.

\section{RESULTS}

Cross-sectional study. The first part of the study included 252 patients with $\mathrm{CF}$, in which $146(58 \%)$ had chronic $P$. aeruginosa pulmonary infection and 46 patients $(18 \%)$ had diabetes (CFDM). The mean age at onset of CFDM was $20.6 \mathrm{y}$ (range, 3-40 y). Two patients (4\%) exhibited CFDM before the age of 10 , and 34 patients $(74 \%)$ were $>15 \mathrm{y}$ old at the time of onset of CFDM. Of the 39 patients (15\%) who developed IGT, $4(10 \%)$ progressed to CFDM and $23(59 \%)$ reverted to NGT, whereas $12(31 \%)$ manifested IGT a second time. The CFDM group of patients had been chronically infected with $P$. aeruginosa for 8.7 y (range, 0-23.9 y) before onset of CFDM. The CFDM group of patients had a significantly higher number of bacterial precipitins and of precipitins against $P$. aeruginosa than the nondiabetic group of patients (Table 1). CFDM patients also show a variable and high level of IgG antibodies to the $60-\mathrm{kD}$ GroEL of $P$. aeruginosa compared with the nondiabetic group and with healthy persons evaluated by immunostaining (Fig. 1). However, the number of bacterial precipitins and the level of $\mathrm{IgG}$ antibodies to the $60-\mathrm{kD}$ GroEL of $P$. aeruginosa are correlated with age as shown in Figure 2. Consistently, the difference in precipitins between the diabetic group and the nondiabetic group is related to the difference in the mean age ( 26 versus $15 \mathrm{y}$ ) between these groups (Table 1$)$. This was confirmed by a test that showed no difference in number of bacterial precipitins or in GroEL-specific IgG antibodies between diabetic versus nondiabetic CF patients crossmatched for age and sex (Table 2).

Longitudinal studies. In a prediabetic CF patient, from whom sera were collected in a 5-y period during onset of CFDM, the samples were evaluated for blood glucose tolerance, number of bacterial precipitins, and level of IgG antibodies against the $60-\mathrm{kD}$ GroEL of $P$. aeruginosa (Fig. 3). This revealed an increase of the GroEL-specific IgG antibodies of $69.4 \%$ before onset of CFDM. During the same period, the patient exhibited chronic $P$. aeruginosa infection as indicated.

A study including 29 prediabetic and nondiabetic CF patients matched in pairs for age, sex, and chronic $P$. aeruginosa pulmonary infection was performed (Table 3). Patient sera were retrospectively selected from a collection of sera from all CF patients and included 673 serum samples, of which 420 were prediabetic samples, and 676 samples were included in the control group. This study included evaluation of the number of precipitins against $P$. aeruginosa in a 9-y period, initiated $6 \mathrm{y}$ before the onset of CFDM for each patient (Fig. 4, $A$ and $B$ ). At entry into the study ( $-6 \mathrm{y}$ ), no significant difference 
Table 2. Cross-matched diabetic vs. nondiabetic CF patients matched for age and sex

\begin{tabular}{|c|c|c|c|}
\hline Variable & CFDM & CF alone & $p$ value $\|$ \\
\hline No. of patients $(\mathrm{M} / \mathrm{F})$ & $34(17 / 17)$ & $34(17 / 17)$ & \\
\hline Age in years (median, range) & $25(13-45)$ & $25(13-43)$ & 0.859 \\
\hline Glucose tolerance $\dagger$ (median, range) & $14.3(12-21)^{*}$ & $7.3(5-9)^{* *}$ & $<0.001$ \\
\hline No. of $P$. aeruginos $a$ precipitins $\$$ (median, range) & $22(0-42)$ & $21(0-38)$ & 0.636 \\
\hline Specific $P$. aeruginosa GroEL $\mathrm{Ab} \S$ (median, range) & $0.629(0.01-1.90)$ & $0.381(0.01-1.44)$ & 0.082 \\
\hline
\end{tabular}

* Three observations by fasting (morning) glucose tolerance (mean, 10.6; range, 10-11).

** Twelve observations by fasting (morning) glucose tolerance (mean, 5.; range, 4-8) and glucose tolerance is performed within the same year as the corresponding CFDM observation.

$\dagger$ Determined by 2-h OGTT (capillary plasma glucose concentration in $\mathrm{mM}$ ).

$\$$ Determined by CIE.

$\S$ Determined by ELISA (units).

\| Mann-Whitney $U$ test.

Table 3. Clinical data of diabetic vs. nondiabetic CF patients cross-matched for age, sex, and precipitins against $\mathrm{P}$. aeruginosa

\begin{tabular}{|c|c|c|c|}
\hline Variable & CFDM & CF alone & $\begin{array}{c}p \\
\text { value } \S\end{array}$ \\
\hline Number of patients $(\mathrm{M} / \mathrm{F})$ & $29(17 / 12)$ & $29(17 / 12)$ & \\
\hline Age in years (median, range) & $21.0(13-40)$ & $19.5(13-38)$ & 0.655 \\
\hline \multicolumn{3}{|l|}{ at entry of study $(-6$ y) } & \\
\hline \multicolumn{4}{|l|}{ Number of patients with $P$. aeruginosa infection } \\
\hline Chronic infection & 15 & 15 & \\
\hline Number of $P$. aeruginosa precipitins (median, range) & $16.0(0-45)$ & $18.0(0-39)$ & 0.930 \\
\hline
\end{tabular}

* Two observations by fasting (morning) glucose tolerance (mean, 5.6; range, 5-6), and glucose tolerance is performed within the same year as the corresponding CFDM observation.

$\dagger$ Determined by 2-h OGTT (capillary plasma glucose concentration in $\mathrm{mM}$ ).

$\$$ No colonization ( $<1$ precipitin), intermittent colonization ( $\geq 1, \leq 15$ precipitins) and chronic infection ( $>15$ precipitins) determined by CIE.

$\S$ Mann-Whitney $U$ test.

was found in the median number of $P$. aeruginosa precipitins between the prediabetic group and the matched nondiabetic group $(p=0.9304)$. The number of $P$. aeruginosa precipitins increased in both groups during the 9-y period $(p<0.0001)$; serial Mann-Whitney $U$ tests between each observation in the prediabetic group with the corresponding observation of the nondiabetic group did not reveal any significant difference.

Sera collected from the same 29 prediabetic CF patients as above were evaluated by ELISA for IgG antibodies to the $60-\mathrm{kD}$ GroEL of $P$. aeruginosa in a 5-y observation period, initiated 3 y before the onset of CFDM. This study included 320 serum samples, of which 167 were prediabetic samples, and 349 samples were included in the control group. The level of GroEL-specific IgG antibodies varied in these patients from $0.18 \mathrm{U}$ (range, $0.12-0.22 \mathrm{U}$ ) in a low-titer patient to $86.91 \mathrm{U}$ (range, 49.22-187.08 U) in a high-titer patient at onset of CFDM (not shown). In addition, the level of $\operatorname{IgG}$ antibodies to $P$. aeruginosa GroEL was found to vary (up to 100 -fold) within a given patient during the observation period. The IgG antibodies to $P$. aeruginosa GroEL were calculated as a percentage of the mean (normalization), as shown in Figure 4, $C$ and $D$. This revealed for the prediabetic group a median increase of $5.4 \% / y$ during the observation period ( $\rho=0.787$; $p=0.0001)$ and a relative and significant increase of $24.6 \%$ of GroEL-specific IgG antibodies during a 9-mo period (from -1 to $-0.25 \mathrm{y})$ before onset of CFDM $(p=0.0084)$. The cross- matched nondiabetic CF patients were followed in the same observation period and showed a median level of GroELspecific IgG antibodies of $4.0 \mathrm{U}$ (range, $0.6-105.3 \mathrm{U}$ ) at the matched time of onset of CFDM in the prediabetic group of patients (not shown). There was no significant difference between the prediabetic group and the cross-matched group $1 \mathrm{y}$ before, at onset, and $1 \mathrm{y}$ after the time of onset of CFDM ( $p>$ 0.3 ). The IgG antibody level to $P$. aeruginosa GroEL was normalized in the matched nondiabetic group of patients (Fig. $4 D)$. An increase of $6.2 \% / \mathrm{y}$ was found during the observation period ( $\rho=0.831 ; p=0.0001)$, and this group showed no significant increase in GroEL-specific antibodies at any time during the observation period.

\section{DISCUSSION}

In CF patients, chronic lung infections caused by $P$. aeruginosa are difficult to treat and impossible to eradicate because of ineffective clearance by the CF lungs and development of antibiotic resistance in the bacteria (14). Despite development of antibiotic resistance, aggressive therapy using specific antibiotics is beneficial to the patient. By use of aggressive therapy for the last two decades, the CF Center in Copenhagen improved the CF survival rate markedly (15). However, any therapy depends on a good method for diagnosis. In addition to conventional bacterial culture and microscopy, diagnosis of 

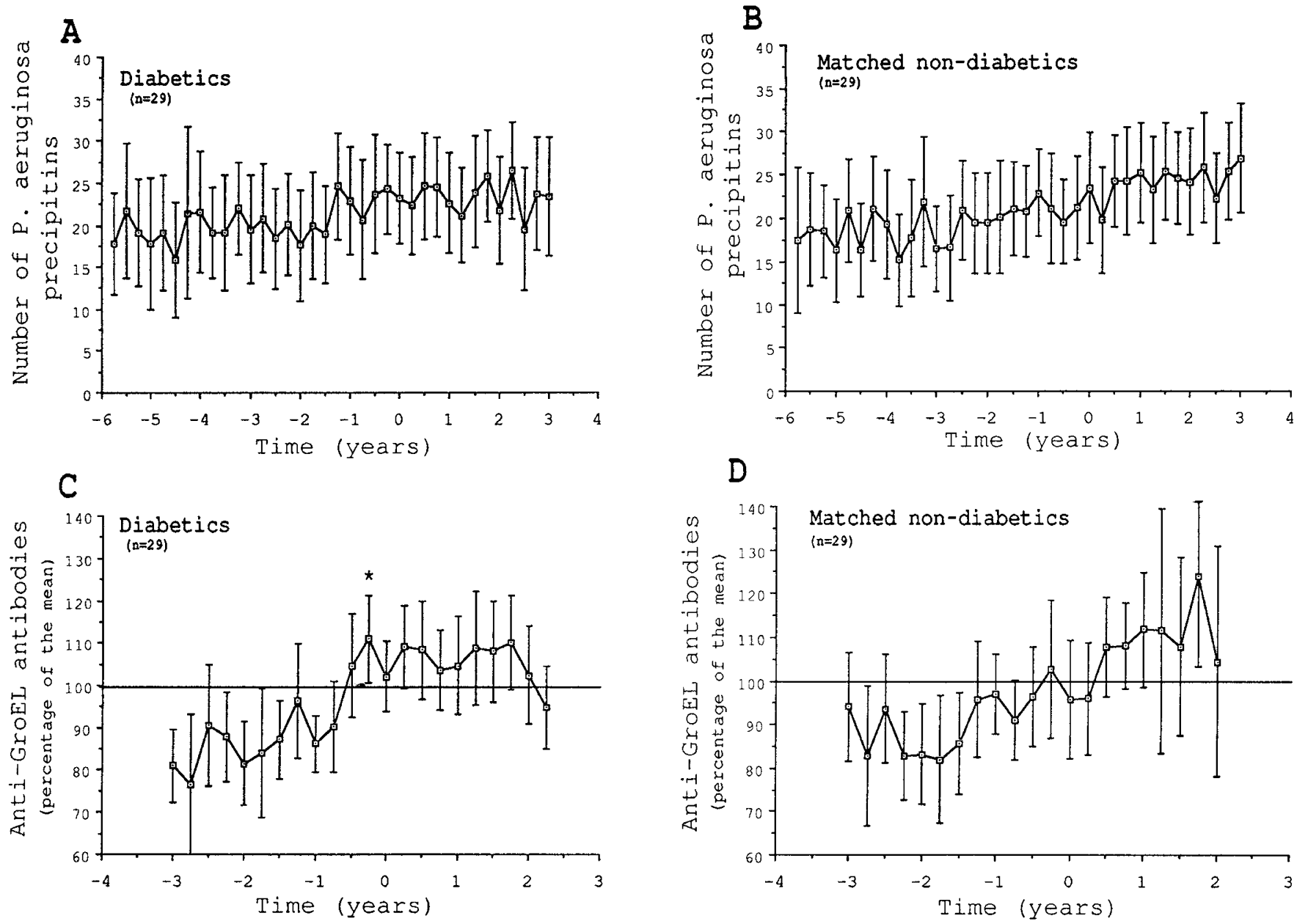

Fig. 4. Longitudinal study of prediabetic $(A$ and $C)$ and cross-matched nondiabetic $(B$ and $D)$ CF patients, matched in pairs for age, sex, and chronic $P$. aeruginosa infection. Serum samples were evaluated for number of $P$. aeruginosa precipitins during development of CFDM ( $A$ and $B$ ), and for GroEL-specific $\mathrm{IgG}$ antibodies determined by ELISA and calculated as the percentage of the mean $(C$ and $D)$. Time $=0$ indicates the onset of CFDM in the prediabetic group of patients. Error bars represent $95 \%$ CI. $* p=0.0084$ compared with $-1 \mathrm{y}$.

chronic pulmonary infection is made by measuring the number of precipitins against bacterial pathogens by CIE. CIE along with immunostaining and ELISA have been used in this study to measure precipitins against various bacteria plus $\operatorname{IgG}$ antibodies against the $60-\mathrm{kD}$ GroEL of $P$. aeruginosa. In the cross-sectional study, major increase in precipitins, bacterial as well as $P$. aeruginosa-specific precipitins, is observed at an age of 14-15 y (Fig. 2, $A$ and $B$ ). Interestingly, CFDM is diagnosed in the majority of patients at an age of $20 \mathrm{y}$. It is possible that CFDM is caused by an infection; however, we failed to find any correlation between precipitins and CFDM when using age- and sex-matched patients (Table 2).

A search for a different method to evaluate the immune response in CF patients was performed. This led to the evaluation of serum IgG antibody response against a $60-\mathrm{kD}$ GroEL of $P$. aeruginosa in prediabetic CF patients. This hsp of the hsp60 family is $52 \%$ identical to the homologous human hsp60 (8), and high levels of antibodies to hsp60 have previously been seen in CF patients (16). Because of the homology between bacterial GroELs and human hsp60, the hsp60 antibody detected is most likely caused by ongoing pulmonary infections in these patients.
The finding in this study of a relative increase in the $\operatorname{IgG}$ antibody response to the $60-\mathrm{kD}$ GroEL of $P$. aeruginosa a few months before onset of CFDM (Fig. 4C) could be a result of activated B cells in response to the $60-\mathrm{kD}$ GroEL of $P$. aeruginosa or in response to other microbial GroEL proteins produced in the course of microbial infections. Thus, a microbial infection may precede and perhaps be a cause of the progressive destruction or down-regulation of pancreatic $\beta$ cells in CF.

Early studies show that the number of islets of Langerhans seems to be normal in CFDM (17), but later studies have established by immunocytochemical techniques that the density and number of islets in CFDM are reduced (18). A relative preservation of $\beta$ cells in CFDM may explain the absence of ketoacidosis in the disease (19) and explain the mild nature of CFDM. Several mechanisms may apply to the development of CFDM. The most prevalent theory is that CFDM is caused by a slow, year-long fibrosis of the exocrine pancreatic tissue with a subsequent strangulation of the islets of Langerhans and thereby reduced number of $\beta$ cells (20). The second event may be an autoimmune destruction or down-regulation of pancreatic $\beta$ cells, a similar mechanism found in autoimmune IDDM. 
However, CFDM and IDDM are different in many ways. The prevalence of CFDM increases with age, which is not the case in IDDM (21), CFDM shows no ketoacidosis as is found in IDDM, and progression toward diabetes in CFDM is considered mild compared with IDDM. Given the range in age at which diabetes develops in CF (3-40 y), several mechanisms may apply to CFDM, strangulation as well as autoimmune related. Against CFDM being autoimmune related is the conflicting evidence concerning the presence of islet cell antibodies in CF. This marker has been found to be present in $15 \%$ of patients with $\mathrm{CF}$ compared with a prevalence of $0.5 \%$ in a normal population (22). However, others have either not found islet cell antibodies present in CF (23) or only found them in $3 \%$ compared with a frequency of $2 \%$ to $3 \%$ in healthy controls, which was not different for diabetic versus nondiabetic CF patients (24). In a recent study, a group of $28 \mathrm{CF}$ patients were followed in a 10-y period; 12 developed diabetes and were found to be more frequently linked with the genotype $\Delta 508$ as compared with the nondiabetic patients, whereas the latter group was linked with the genotype N1303 K (25). This study suggests that the $\Delta 508$ mutation may induce susceptibility to CFDM, whereas the $\mathrm{N} 1303 \mathrm{~K}$ mutation may give protection. In an earlier study, however, including $215 \mathrm{CF}$ patients, of which 211 had the $\Delta 508$ mutation, we found no difference between patients who were homozygous or heterozygous for the $\Delta 508$ mutation, and endocrine pancreatic function was normal in $72.5 \%$, impaired in $12.3 \%$, and diabetic in $15.2 \%$ of the patients, with no difference between CF patients who were homozygous (21). This study indicates that there is no correlation between the $\Delta 508$ mutation and development of CFDM. The finding, however, that CFDM may be related to the genotype HLA DQB1 (26) and the finding in this study of an increase in the $60-\mathrm{kD}$ GroEL antibody in prediabetic CF patients indicate an immunologic complicity.

Development of IGT is common in CF, although most of the cases will revert to NGT (1). Some patients, however, acquire IGT repeatedly and subsequently develop CFDM (1). Interestingly, Elias et al. $(4,5,27)$ found the hsp-induced diabetes to be transient in the nonobese diabetic mouse model $(4,27)$ as well as in standard mice using the peptide p277 of hsp60 (5). Development of IGT in CF might therefore be a result of an autoimmune-related $\beta$-cell destruction or down-regulation, depleting the $\beta$-cell mass to the extent of impairing tolerance without necessarily progressing to CFDM. CFDM could well be related to the experimental hsp-induced diabetes by sharing an early environmental event such as a microbial infection, acting in genetically susceptible individuals. The inducible and protective role of hsp-reactive $\mathrm{T}$ cells on diabetes in mouse models further substantiates the possible role of bacterial 60-kD GroELs on CFDM. Extensive studies need to be performed to determine the possible impact of infection on diabetes in $\mathrm{CF}$.

Acknowledgments. The authors thank Kalai Mathee for valuable comments and corrections of the manuscript.

\section{REFERENCES}

1. Lanng S, Hansen A, Thorsteinsson B, Nerup J, Koch C 1995 Glucose tolerance in patients with cystic fibrosis: five year prospective study. BMJ 311:655-659

2. Cohen IR 1997 The Th1/Th2 dichotomy, hsp60 autoimmunity, and type I diabetes. Clin Immunol Immunopathol 84:103-106

3. Birk OS, Elias D, Weiss AS, Rosen A, van der Zee R, Walker MD, Cohen IR 1996 NOD mouse diabetes: the ubiquitous mouse hsp60 is a beta-cell target antigen of autoimmune T cells. J Autoimmun 9:159-166

4. Elias D, Markovits D, Reshef T, van der Zee R, Cohen IR 1990 Induction and therapy of autoimmune diabetes in the non-obese diabetic (NOD/Lt) mouse by a $65-\mathrm{kDa}$ heat shock protein. Proc Natl Acad Sci U S A 87:1576-1580

5. Elias D, Marcus H, Reshef T, Ablamunits V, Cohen IR 1995 Induction of diabetes in standard mice by immunization with the p277 peptide of a $60-\mathrm{kDa}$ heat shock protein. Int Arch Allergy Immunol 108:345-349

6. Blanas E, Carbone FR, Allison J, Miller JF, Heath WR 1996 Induction of autoimmune diabetes by oral administration of autoantigen. Science 274:1707-1709

7. Cohen IR 1993 On the regulation of EAE. Int Rev Immunol 9:243-249

8. Jensen P, Fomsgaard A, Høiby N, Hindersson P 1995 Cloning and nucleotide sequence comparison of the groE operon of Pseudomonas aeruginosa and Burkholderia cepacia. Apmis 103:113-123

9. Høiby N, Hertz JB, Sompolinsky D 1980 Antibody response in patients with Pseudomonas aeruginosa infection to a 'common antigen' from $P$. aeruginosa analysed by means of quantitative immunoelectrophoretic methods. Acta Pathol Microbiol Scand Sect C Immunol 88:149-154

10. Jindal S, Dudani AK, Singh B, Harley CB, Gupta RS 1989 Primary structure of a human mitochondrial protein homologous to the bacterial and plant chaperonins and to the 65-kilodalton mycobacterial antigen. Gene 84:295-302

11. Høiby N 1974 Epidemiological investigations of the respiratory tract bacteriology in patients with cystic fibrosis. Acta Pathol Microbiol Scand Sect B Microbiol Immunol $82: 541-550$

12. Høiby N, Flensborg EW, Beck B, Friis B, Jacobsen SV, Jacobsen L 1977 Pseudomonas aeruginosa infection in cystic fibrosis: diagnostic and prognostic significance of Pseudomonas aeruginosa precipitins determined by means of crossed immunoelectrophoresis. Scand J Respir Dis 58:65-79

13. World Health Organization 1985 Diabetes mellitus: report of a WHO Study Group. Geneva, World Health Org Tech Rep Ser 727:1-113

14. Høiby N, Giwercman B, Jensen ET, Pedersen SS, Koch C, Kharazmi A 1994 Mechanism of action of antibiotics in chronic pulmonary pseudomonas infection. Adv Pharmacol 30:53-84

15. Frederiksen B, Lanng S, Koch C, Høiby N 1996 Improved survival in the Danish center-treated cystic fibrosis patients: results of aggressive treatment. Pediatr Pulmonol 21:153-158

16. de Graeff-Meeder ER, Rijkers GT, Voorhorst Ogink MM, Kuis W, van der Zee R, van Eden W, Zegers BJ 1993 Antibodies to human HSP60 in patients with juvenile chronic arthritis, diabetes mellitus, and cystic fibrosis. Pediatr Res 34:424-428

17. Rosan RC, Shwachman H, Kulczycki LL 1962 Diabetes mellitus and cystic fibrosis of the pancreas. Am J. Dis Child 104:625-634

18. Soejima K, Landing BH 1986 Pancreatic islets in older patients with cystic fibrosis with and without diabetes mellitus: morphometric and immunocytologic studies. Pediatr Pathol 6:25-46

19. Rodman HM, Doershuk CF, Roland JM 1986 The interaction of two diseases: diabetes mellitus and cystic fibrosis. Medicine 65:389-397

20. Sheppard MN 1995 The pathology of cystic fibrosis. In: Hodson ME, Geddes DM (eds) Cystic Fibrosis. Chapman \& Hall Medical, London, pp 131-149

21. Lanng S, Schwartz M, Thorsteinsson B, Koch C 1991 Endocrine and exocrine pancreatic function and the delta F508 mutation in cystic fibrosis. Clin Genet 40:345-348

22. Marner B, Bille G, Christy M, Damsgaard EM, Garne S, Heinze E, Larsen S, Lernmark Å, Mandrup-Poulsen T, Nerup J, Schroll M 1991 Islet cell cytoplasmic antibodies (ICA) in diabetes and disorders of glucose tolerance. Diabet Med 8:812816

23. Stutchfield PR, O'Halloran SM, Smith CS, Woodrow JC, Bottazzo GF, Heaf D 1988 HLA type, islet cell antibodies, and glucose intolerance in cystic fibrosis. Arch Dis Child 63:1234-1239

24. Lanng S, Thorsteinsson B, Pociot F, Marshall MO, Madsen HO, Schwartz M, Nerup J, Koch C 1993 Diabetes mellitus in cystic fibrosis: genetic and immunological markers. Acta Paediatr 82:150-154

25. Cucinotta D, De Luca F, Scoglio R, Lombardo F, Sferlazzas C, Di Benedetto A, Magazzu G, Raimondo G, Arrigo T 1999 Factors affecting diabetes mellitus onset in cystic fibrosis: evidence from a 10-year follow-up study. Acta Paediatr 88:389-393

26. Carrington M, Krueger LJ, Holsclaw DJ, Iannuzzi MC, Dean M, Mann D 1994 Cystic fibrosis-related diabetes is associated with HLA DQB1 alleles encoding Asp-57molecules. J Clin Immunol 14:353-358

27. Elias D, Reshef T, Birk OS, van der Zee R, Walker MD, Cohen IR 1991 Vaccination against autoimmune mouse diabetes with a T-cell epitope of the human $65-\mathrm{kDa}$ heat shock protein. Proc Natl Acad Sci U S A 88:3088-3091 